\title{
The Ethics of Cooperation in Business
}

\author{
Yotam Lurie \\ Department of Management, Ben-Gurion University of the Negev, Beer-Sheva, Israel \\ Email: yotam@som.bgu.ac.i
}

Received 17 February 2016; accepted 2 May 2016; published 5 May 2016

Copyright (C) 2016 by author and Scientific Research Publishing Inc.

This work is licensed under the Creative Commons Attribution International License (CC BY).

http://creativecommons.org/licenses/by/4.0/

(c) (i) Open Access

\section{Abstract}

As cooperative ventures and strategic alliances have increased in numbers, there is need for an analysis which does not proceed from presumption that singular-person action is the only form of action. When doing things with others, certain wrongs become possible that solo activity does not recognize. Moreover, such an alternative might help identify explanations and ways firms might better manage cooperative ventures. Philosophers in the field of business ethics can contribute to this discussion by bringing insight to a concept that is now at the focus of the business and academic community. This paper aims to clarify the concept of cooperation and more specifically the notions of cooperative action. At least some obligations seem to arise out of the very fact that we are in some activity together. The questions posed in connection with it are such as, "What exactly do we mean by cooperation? What are the key characteristics of cooperation? Is it possible to delineate a generic typology of various kinds of cooperation?" Initially the paper fleshes out the formal features of the concept. Next, the paper considers the types of cooperation likely to exist in the business world, offering four schemes of cooperation that progress from the more limited to the more advanced forms of cooperation. Consequently, it discusses the idea of cooperation in business from an ethical perspective.

\section{Keywords}

Cooperation, Alliances, Associations, Ethics, Business

\section{Introduction}

Since the 1990s the term "cooperation" has become a buzzword in the business world. It permeates discussions and provides a slogan that commands attention and directs perspectives. The banner of "cooperation" is hoisted in courses taught in business schools, in articles published in academic journals and at international conferences (Beamish \& Killing, 1997). Accordingly, many businesses as well as government and nongovernmental organizations have come to view cooperation as a worthwhile goal. In trying to debunk some of the traditional business myths regarding greed, selfishness and individualism, the idea of cooperation has become an important 
strategic and moral ideal within the business world. In keeping with this trend, advocates of cooperation in business note that just as a political community is more than a collection of individuals, a business community is and ought to be more than just an eclectic collection of firms, each striving for its own self-gain. To remain true to the concept of a community, business ethicists argue that a business community should strive for cooperation among its various affiliates. Stakeholder theory (Freeman, 1984) and the more recent notion of corporate citizenship (Waddock, 2002), although different from one another, are two catch phrases associated with this more cooperative vision of business.

The aim of this paper is to take the first steps towards clarifying the very concept of "cooperation", a concept as difficult to understand, as it is popular. The questions posed in this regard include: "What exactly do we mean by cooperation? What are the key characteristics of cooperation? Is it possible to delineate a generic typology of various kinds of cooperation, and if so, what might such a typology look like?" Such questions relate to the formal features of the concept of cooperation. At the beginning of the paper, the answers to these questions are outlined. Then, the paper fleshes out the formal features of the concept in the context of various forms of business cooperation, considering the types of cooperation likely to exist in the business world. Consequently, the idea of cooperation in business is examined from an ethical perspective. To perform this analysis effectively, the paper first highlights the more mundane examples of business cooperation and then progresses to forms of cooperation that involve a deeper sense of collaboration. Examples are taken from the realms of sports and politics, which like business and economic affairs include an important element of strife and competition-all this with the goal of demonstrating that cooperation and competition are not necessarily opposed. The result is that an ethical conception of cooperation that is relevant to the business world of today is delineated.

\section{Situating the Discussion}

In the past, when a company signed a simple product distribution agreement, the rights and obligations of the parties were quite well defined. In contrast, now when two businesses establish a cooperative alliance for a joint research and development project, the terms of the agreement are not self-evident and must be determined on the basis of the actual cooperative input of the parties over time. New cooperative activities, also known as alliances, have come to the forefront: joint purchase centers, technological agreements, joint export enterprises, joint ventures and industrial alliances with local or foreign partners all exhibit attempts to develop various forms of cooperative activities.

Growth in cooperative ventures can be attributed to a range of factors. First, the complexity and the rate at which technological breakthroughs occur make it almost impossible for a company to be at the forefront in every field. Related to this, it can be noted that many areas of activity, such as computer technology, require integration between different sectors, including communication, hardware, software and microchip manufacturers. Companies are thus forced to specialize, while working in cooperation with partners, in order to reduce risks and costs. Another reason has to do with globalization. Globalization requires businesses to penetrate often less familiar and less accessible markets (Argandona, 1999; Held, 1999).

As cooperative ventures and strategic alliances have increased in numbers, scholars from many fields, including among others the disciplines of Strategic Management, Finance, and Organizational Studies, have sought to identify explanations and ways firms might better manage cooperative ventures (Ring \& Van de Ven, 1994). Prior research on alliances in the area of strategic management has focused mainly on trying to understand the design, the evolutionary path and the ultimate success of alliances. The key questions in this respect have to do with each stage in the sequence of events in alliances. This sequence includes the decision to enter into an alliance, the choice of a partner, the choice of a structure for the alliance, and the dynamic evolution of the alliance (Gulati, 1998; Reuer et al., 2001). From an economic and financial point of view, research on alliances has focused primarily on the economic value of cooperative ventures. A significant issue in this context has to do with attempts to estimate the effect of cooperation on the firm’s performance (e.g., Balakrishnan \& Koza, 1993). There is evidence that, on average, alliances do create economic value (Chan et al., 1997; Annad \& Khanna, 2000), even though there is also research, which demonstrates that half the alliances formed end up failing (Harrington, 1985; Kogut, 1989). Consequently, several studies have sought to identify the magical formula for cooperative success. It is clear that many of the ingredients relevant for cooperative success are organizational in nature such as, for example, flexibility in management, the building of trust with partners, and regular exchange of information with partners (Anderson \& Narus, 1990; Kanter, 1989; Bleeke \& Ernst, 1991). Because cooperative ventures can have such a diverse organizational structure, studies about alliances from an organiza- 
tional standpoint have identified an array of choices organizations face in structuring their governing structure and cooperative culture (e.g., Powell, 1990).

Philosophers in the field of business ethics can contribute to this ongoing discussion by shedding light on the concept of cooperation, which is now at the focus of the business community, articulating our central social, political, economic and moral ideals in connection with it. It is important to remember that long before applied ethics turned into a series of attempts to resolve moral problems and ethical dilemmas, moral philosophy had always played an important role in articulating our central social, political, economic and moral ideals. Thus, for example, notions such as integrity, friendship, honesty, freedom and equality all received serious philosophical attention. "Cooperation" is a concept in need of a context-a concept that is awaiting serious philosophical attention. This need for a richer philosophical context is further amplified when we see the limitations with the kinds of discussions of cooperation that takes place in, for example, game strategy (Axelrod, 1984) or in rational choice theory (e.g., Gauthier, 1986). These discussions attempt to answer the normative question "when should a person cooperate" as they attempt to provide a justificatory framework for cooperative behavior. They lean, however, on a rather thin conception of human and organizational cooperation. Consequently, they fail to provide a sufficiently rich analytic description and explanation of what cooperation is.

\section{Formal Features of the Concept of Cooperation}

It may be useful to begin by dispelling three common misconceptions about the nature of cooperation. The notion of cooperation becomes clearer when it is distinguished from three related, though different misconceptions. 1) Cooperation is not about "providing assistance". At times various individuals or organizations help by trying to assist other individuals or organizations. The proverbial well-intentioned Boy Scout helping the old lady cross the street is assisting the lady, not cooperating with her. The Red Cross and other international relief organizations regularly help refugees in impoverished areas of the world. Their goal is to provide aid, but they are not necessarily cooperating with the local refugees whom they help. Clearly if the old lady and the refugees do not cooperate, helping them is not only difficult, but also virtually impossible. Nevertheless, the act of providing help or assistance is a different kind of behavior from that which embodies in it a robust concept of cooperation. Merely providing assistance does not embody a robust concept of corporation because the parties in these examples are on two extreme ends of what is basically a single action performed by only one of them, the agent of the benevolent act. The other party is simply a complying recipient. It lacks in reciprocity. Patients in hospitals cooperate with their doctors, but it would be misleading to describe the hospital as a cooperative institution, simply because doctors assist patients in overcoming their illness, and patients willingly submit to what the doctors do to them. A robust concept of cooperation requires more than the performance of a benevolent action by one party and the existence of another party who submits to that action. 2) Cooperation is also not about "tolerance". Over the years the large monotheistic religions in the West have learned to tolerate one another. This is not to say that cooperation of any sort exists between the religions, even when they co-exist within the political framework of a single country. Tolerance relates to the acceptance of others despite significant disagreements and differences in modes of life. As a philosophical concept, it is about allowing others to do things that do not appeal to us. Tolerance pertains to attitudes and views espoused by human beings and relates to actions not taken, rather than actions taken. In contrast, cooperation is far more than a world-view espoused by individuals; it is not a passive, but very active approach. 3) Furthermore, cooperation is also not simply "being in a relationship" with someone. When two countries decide to establish diplomatic relations, they have not automatically decided to cooperate. Even when they later expand their diplomatic relationship to cultural and economic relations, allowing for the sale and marketing of their different products, it does not follow that by merely exchanging goods they have created cultural or economic cooperation. Similarly, within a large organization, the employees may strive to maintain good and friendly relations with each other, even when they have very little professional interactions and thus, since each employee basically does their own thing, there is virtually no cooperation in terms of the individuals actual work, such as might exist, for example, among team members in a high-tech research and development company.

On a more positive note, we may begin by remarking that cooperation is a form of behavior that requires collaboration between different parties. Unlike walking or washing, cooperation is a behavior that cannot be practiced by a single party. It takes two to tango, and it takes at least two individuals in a joint effort to bring about a form of behavior that manifests cooperation. Unlike the tango, however, cooperation is not limited to only two individuals. It is a form of behavior that consists of joint efforts known as "teamwork", and it allows for many 
individuals to participate through many different kinds of behavior on their part. Cooperation is not the name of single activity, like "dancing" or "swimming", but rather a social way of doing things by different kinds of activities.

The difficulty in clarifying the concept centers around both its intentional component, its goal directness, and the way in which goals are pursued by means of cooperation. Delineating the conceptual boundaries of the goals and how they are pursued through cooperation is tricky. Ants seem to cooperate in seeking their subsistence. Snakes do not. Ants are social animals, and snakes are not. Like ants, monkeys are also social animals, yet they usually do not cooperate in seeking food except under special circumstance (Southwick, 1963; de Waal, 1989: pp. 109-110, p. 200; Watts, 2002). So what is it about the social milieu of ants that leads us to say that they engage in cooperation? Perhaps it can be said that although individual ants may perform different tasks, they appear to work together in pursuit of a common goal. This is what led philosophers such as Hobbes to remark that certain creatures, such as ants and bees, are social animals in the sense that their common will naturally coincides with their private will (Hobbes, 1992: p. 119). According to this distinction, snakes and human beings lack a naturally common will. But unlike snakes, human beings can indeed cooperate within a social context. Hobbes' presumption, however, that ants have a will, not to mention a common will, is a highly disputed claim since it presupposes that ants have intentions and propositional attitudes (Malcolm, 1972; Davidson, 2001). Possibly, the justification for Hobbes' intuition that ants do indeed cooperate is the fact that at a purely behavioral level ants seem to be working in collaboration, like a team, in pursuit of a common goal. One need not assume a common will for cooperation to exist.

Does cooperation require, therefore, collaboration in the pursuit of a common goal? Must cooperation include a common goal? Initially it may seem that a common goal is not always a prerequisite for cooperation. Farmers and merchants collaborate in a mutual enterprise of cooperation, though each party has different goals. The goal of farming is to grow produce or raise farm animals. The goal of merchants is to sell goods. The parties cooperate with each other to their mutual benefit. Each party, however, makes different contributions to the cooperative endeavor, and each has its own set of goals for any particular activity. It may be argued, though, that the extent to which farmers and merchants cooperate, they have a common goal. Both are interested in making the produce available to buyers and in making money by selling them. Thus, they do have a common goal. Note that their common goal in each case is only a means to achieve their individual goals—namely, either making money, supporting their families, attaining happiness and the like. The common goal they are actively pursuing is, in this case, directly related to what unites them. They rely on each other to achieve both their individual and mutual goals. However, their common goal is not sufficiently part of their specific goals. Both have an interest in attaining the best prices for the products, but their interests actually clash. So while it may appear that the farmers and merchants are working as a team, in fact they have conflicting interests that team members should not have.

Compare the common goal that farmers and merchants have with two passengers on a train, each seeking to get to their home. They too may be said to have a common goal, but they are not cooperating in pursing it. Some would like to distinguish here between a common goal and the same goal. But what if the two riders on the train lived in the same home? Clearly, they would then have not only a common goal, but also the same goal in mind when riding the train. Nonetheless, this would still not render their behavior into a form of cooperation. Similarly, two thieves may both try to kill the detective who is out to capture them. Their actions have a common goal, but if they each acted separately and without knowing about the other, they did not cooperate.

What these examples demonstrate is that, although a common goal is presupposed in cooperation, it is difficult to use the concept of a common goal to distinguish between what is and what is not cooperation. Moreover, a common goal is not a sufficient condition for rendering a certain form of behavior into a form of cooperation. To the extent that cooperation requires a common goal, it requires joining efforts in working together for it, not simply having it or working for it separately. During the student demonstrations in the late sixties and seventies against the policy of the United States government in South-East Asia, President Nixon liked to say that he and the students shared a common goal: that of bringing peace to the region. This, despite the fact they were not cooperating at all. They were not cooperating precisely because they were not working together to achieve this goal. Indeed they were not doing so, because they had opposing views as how it should be achieved. The conceptual difficulty here is getting clear about what "working together for a common goal" involves, for this is the backbone in the concept of cooperation.

Thus, cooperation is also more than just a form of collaboration, as the outcome should be a joint action. Citizens who collaborate with an enemy that has occupied their country, whether for money or for security, are 
not exactly engaged in a cooperative task with the enemy. While they might be working together with the enemy, the enemy and the citizens of the occupied country do not have common goals. Cooperation has to do with working together, in collaboration, in pursuit of common goals.

Although the concept of cooperation as articulated here is relatively new to the business world, it is by no means a new social idea. The ideal of cooperation already played an important role in ancient social theories that undertook to shed light on the nature of human social institutions. Long before the business community discovered the concept of cooperation, political philosophers defined it as a political ideal toward which a community should strive, often without actually mentioning the term cooperation itself, and its conceptual tributaries were explored and described in philosophical tracts. An example in point is Aristotle's well-known discussion of different forms of association, which I suggest should be understood as referring to different forms of cooperation. Book One of his Politics opens with a discussion of three major forms of association, which he classifies as the household, the village and the state. An "association", in Aristotelian terms, is a relationship between two or more people aimed at some good-presumably a common one. The simplest form of association is that between male and female. Since each is powerless to procreate without the other, individuals find it useful to unite as a pair for reproduction. The supreme association, according to Aristotle, is the state because it embraces all others. Aristotle's conception of human life is political, as human beings are deemed to be social creatures. They are distinguished by their initial social roles, which they can only fulfill by cooperation in a joint venture.

Modern conceptions of human nature are different. They take off by positing human beings as individuals that are all the same in their essential human features and natural rights. Nonetheless, they turn out to be creatures that must rely on cooperation to subsist. Even within the liberal political ideology of the $18^{\text {th }}$ century, an ideology that placed a very high value on individualism and personal autonomy, cooperation was taken to be a necessary condition for the individual to flourish. Hobbes' very basic and raw social contract is based on cooperation. He suggests, "that a man be willing, when others are so too, as far forth as for peace and defense of himself he shall think it necessary, to lay down his right to all things, and be contented with so much liberty against other men as he would allow other men against himself" (Hobbes, 1992: p. 110). In a cooperative venture, partners can come to share knowledge, financial, human and material resources. They share a common goal, but also have a personal interest that may be both independent and antagonistic. Cooperation will thrive only when the partners share enough interest in their cooperation. In other words, a cooperative venture is likely to involve relationships that are simultaneously interdependent and antagonistic (Argandona, 1999).

\section{Four Schemes of Cooperation}

So much for the formal features of the concept of cooperation. In line with John Rawls' celebrated distinction between the concept of justice, which pertains to its formal features, and a conception of justice, which pertains to ways of implementing justice through different social institutions (Rawls, 1971: p. 5f), I would like to distinguish now between four different schemes of cooperation. They are distinguished not on the basis of the size, scope or extent of cooperation, nor on the basis of the actual purpose of the cooperation, but rather on the basis of the type of relationship that emerges between individuals participating in them and on how they share common goals. The point is to articulate what it means to share a common goal, while nevertheless people might have personal interests that are possibly antagonistic. Thus the first line of demarcation between types of cooperation is drawn according to how they manifest "fair terms of cooperation". Put in non-technical terms, the question here is whether the participants are of equal standing and abide by the same rules. The second question to be considered is to what extent cooperation is considered a form of teamwork.

\subsection{Cooperation as a Pooling of Different Assets Together}

The simplest and most straightforward scheme of cooperation has to do with "pooling our different assets together”. The parties work together so that each individual's weaknesses are compensated by the other's strengths. In this sense of cooperation, all participants work towards their own individual private ends. A case in point might be the kind of cooperation that exists between entrepreneurs and the poor communities in which they decide to build their plants. The people in the community need jobs in order to earn money. In return, they offer cheap labor. The residents of the given community are probably happy that the entrepreneur decided to invest in their community instead of in any of the many poor communities around the globe in which people need jobs in order to survive. Entrepreneurs have the skills and the money needed to set up the project and get started. What 
they need is cheap labor. Relationships that embody such cooperative schemes have existed for many years between the developed countries of the west and developing countries in the third world. In terms of cooperation, this kind of relationship might seem exploitive because it does not seem to exhibit fair terms of cooperation and it includes a very limited sense of teamwork. It does not embody recognition of the other's ends as legitimate in and of themselves, and the residents of the poor third world country are not acting out of autonomy. It is in this Kantian sense that there is something ethically lacking from this scheme of cooperation, as clearly each side here takes the other only as a means to accomplishing its own ends.

But this form of cooperation is not limited merely to the possibly exploitive relationships between entrepreneurs and third world countries; it is actually fairly common in our lives and especially in the business world. It is possible to cooperate in the sense of "Pooling of different Assets Together" without the cooperation becoming exploitive. Any large-scale project, such as building a house, requires this form of cooperation. Building a house is neither a one-man project, nor a one-organization project. It requires cooperation between several professionals: the plumber, the electrician and the carpenter. Each professional has a distinct and well-defined task, i.e., their specific goal, but each must also take the other's work into consideration in order to achieve his or her common goal of building the house. They rely on one another. If they did not cooperate they might possibly damage each other's work.

Similarly to the farmers and the merchants discussed in the previous example, each professional has a specific goal that is distinct from their common goal. However, in contrast with the farmers-merchants example, where their common goal was not sufficiently linked with their specific goals and, hence, they had a clash of interests; in the case of different professionals who build a house together their interests and goals are much more intertwined. For example, the roofer's task will be easier if the walls are steady, firm, and evenly built. Similarly the electrician's job presupposes that the plumbing does not leak. The fact that each party in the cooperative endeavor has its own ends in mind is not to say that they are not cooperating. It is possible within this form of cooperation for both sides to see the cooperation as serving their interests and as something that is truly to their advantage. Nevertheless, if this were the only form of cooperation achievable in the business world, we would be lacking much of what makes cooperation such a high social and moral ideal elsewhere. Within this very limited and primary scheme of cooperation there is very little actual teamwork.

\subsection{Hobbesian Cooperation: Self-Interest Restricted}

There are certain situations in which individuals and organizations cooperate by agreeing to play by the same rules. Hobbes' example of what he calls "the second law of nature" in his books Leviathan was of a situation where individuals decide to cooperate by containing some of their natural liberty for the sake of each individual's security. This scheme of cooperation embodies what Rawls calls "fair terms" of cooperation, to which a "difference principle" is added, allowing all to benefit from unequal distribution of assets.

Possibly a clearer understanding of this scheme of cooperation can be grasped by taking an example from the field of sports. Track and field athletes often compete against each other. However, in order for competition to be possible, they must cooperate to some degree. At the very least, they must accept certain ground rules which underlie the practice of competition. They cooperate by accepting the specific rules of their athletic event with respect to technique and proper performance, and they cooperate by coming together at specific times and places in order to compete and pit their abilities against one another. Furthermore, they cooperate by accepting the decisions of their governing board with respect to rules, regulations and meets. It is by adhering to all these things that they cooperate by competing. There would be no winners and no losers, no victories and no defeats if athletes did not cooperate as athletes by undertaking to obey the same rules. The practice of competition as we know it would not exist. In this scheme the different parties to the cooperative endeavor have a common goal, even though it is a very narrowly defined common goal serving only as a basis for allowing each to strive to achieve individual goals. Two athletes competing are not the same as two opposing armies engaged in war. Competition and war are different in the sense that a good athlete can appreciate a fair and honest competition, even to the point of preferring a loss in a good competition from a victory in a poor competition. In the case of war between armies this is not the case. This form of cooperation is made possible because the agents agree to compete with one another under what they take to be fair terms of competition.

\subsection{Cooperation beyond the Zero-Sum Predicament: Self-Interest Reconsidered}

There are certain areas of activity where it seems that we are operating within a zero-sum game. In such cases 
cooperation may be needed either to overcome the predicament or to diminish losses. Consequently, the scarcity of available resources may force us to cooperate. Water, for example, is a limited resource in certain regions such as the Middle East. For years the countries in the region operated within a zero-sum game according to which they reasoned that any water received by one country was that much less water received by the other. Recently, as part of the peace process in the region, the countries are learning to cooperate (Brynen, 2002). They are trying to better utilize the limited amount of water that is available in the region, so that it works to everyone's advantage. In order for cooperation to succeed in such a situation, it is important to overcome the zero-sum predicament. Successful cooperation should result in less waste and better utilization of scarce water resources. Thus, for example, there will be more water for all concerned if less salt and other contaminators leak into the underground aqua-beds, if rivers and streams are not allowed to flow into the sea, if water is not wasted, if water used in homes can be processed and used in farming, and so forth. To bring this about, the countries in the region need to cooperate, even if this entails each country taking separate action in its own territory.

Another example is in the competition between different long distance carriers or different cable television providers. The different companies, which each provide more or less the same service, have agreed to all work on the same basic technological infrastructure. This means that when a customer decides to change from one long-distance carrier to another or from one cable television provider to another, there is no need to install new wires or cables because the companies have agreed to share the same infrastructure. By sharing the same technological infrastructure, the companies are able to provide customers with better products and services than would have been possible had each company had to deploy its own infrastructure.

The product of cooperation is not based on each party performing a specific and well-defined task, but on a mix of efforts and contributions. The two most familiar examples of this type of cooperation are, on the one hand, pollution control and on the other hand the development and production of enormously expensive and complex technologies, two well-documented examples (Maitland, 1985; Arrow, 1973; Solomon, 1994). In most situations of pollution, efforts by one organization would be to no avail. Moreover, as long as the different organizations responsible for pollution are locked in the zero-sum game of classical economic theory, it is against their best interest to combat pollution for it will take a toll on their profit. Cooperation in the fight against pollution is usually only achieved under one of the following two conditions: either through the intervention and regulation of government which takes a strong stand against pollution, or if the losses suffered as a result of pollution were greater than the amount saved through engaging in the activities that pollute the environment. Turning to another kind of example, cooperation is also required in the development and production of new advanced technologies such as Internet, satellites, communication systems or a variety of transportation systems, including seaports, airports, roads and railways. Thus, for instance, the development and production of the space communication satellite in 1970-71, was possible because of the cooperation of at least ten different corporations (AT \& T, Hughes, ABC, CBS, NBC, MCI, Lockheed, and Western Union all monitored by the FCC) in a new technology that would have been beyond the reach of any of them individually (Solomon, 1994: p. 155).

\subsection{The Communitarian Notion of Teamwork: Self-Interest Transformed}

The richest scheme of cooperation is that of a full-bodied form of teamwork. The participants are of equal standing with regard to each other, allowing for a difference principle regarding what they do and how they are paid off. They also share a common goal by which they are associated to one another and through which they define their relationships and the way they operate. Jean Jacques Rousseau can be considered an advocate of this form of cooperation for a political body such as that of the state. In his Social Contract he discusses the transformation people undergo when they abandon the state of nature in favor of the cooperative state he calls civil society (Rousseau, 1967: pp. 22-23). According to Rousseau people thereby gain civil liberty, instead of the natural liberty they once had. This includes the right to property instead of possession based on force and first occupancy; and most importantly, it includes the moral freedom to govern themselves and conduct their affairs by obeying the general will instead of only their natural appetites and motivations. In his earlier writings Rousseau suggests the image of the stag hunt as a paradigmatic example that demonstrates the advantages embedded in this form of cooperation (Rousseau, 1997: p. 163; Skyrms, 2001: pp. 31-43).

A more mundane, though less controversial example of this scheme of cooperation is a basketball team playing a full-court game. When the individual players, skilled as they may be, join a team and learn to play with a team instead of just shooting hoops alone in the parking lot, the players give up the right to sole possession of the ball in favor of new skills such as passing and blocking. Within a team there is a very rich form of tactical 
cooperation. A single player, no matter how talented, cannot accomplish the task that a team can accomplish. Moreover, by joining a team, players can enrich their game through strategic and tactical cooperation. What is interesting about this form of cooperation is that although cooperation requires that one take the other team members into consideration, this form of cooperation makes it possible for the athlete to excel in ways that are not possible for an individual playing alone. This is an area of activity in which athletes cooperate for everyone's benefit as a collective. The goals athletes share are intrinsically linked to the way in which athletes operate together. The way both goals and actions come together embody the shared identity which derives from the cooperative effort. Team sports are not unique in this respect. Musicians playing in an orchestra have similar experiences. In the business world we are familiar with this form of cooperation from the context of organizational ethics. Reviewing these four schemes of cooperation it is evident that the forth scheme presents a sort of ideal in the sense that it provides for the richest sense of teamwork. It is a form of cooperation that allows individuals or organizations to come together within a shared identity where their personal interests are less antagonistic.

\section{The Axiology of Business and Economic Cooperation}

Cooperation has not received enough attention largely because of the Smithian legacy. The Smithian legacy, weakly associated with the views of Adam Smith, the father of modern economics, glorifies self-interest and competition. According to one very popular formulation of this theory, self-interested behavior within a competitive economic situation leads to greater well being, wealth and economic growth for society as a whole. It also states that if people, the famous butcher-brewer-baker passage, acted in an exclusively self-interested manner, they would achieve certain specified successes (Smith, 1776: pp. 26-27). If one is, can be and should only be self-interested, as suggested by the Smithian legacy, the only point of cooperation is then to regulate competition. However, economic interchanges, even between self-interested parties in a competitive situation are not purely adversarial; they depend on cooperation and coordination (Werhane, 1991: pp. 88-96). If private interests can eventually coincide with the general will, there is a much stronger inclination towards cooperation.

Sen has thoroughly discussed this view in order to unveil some of its ethical underpinnings (Sen, 1987: pp. 21-28; Sen, 1993). Two points made by Sen are especially important when trying to justify a discussion of economic cooperation beyond the regulation of competition. First, the motivation of self-interest that the Smithian legacy glorifies is relevant only in the economic context of exchange. However, there are other important economic and business relations, such as production and distribution in which self-interest is not the sole motivation. As Sen reminds us, distribution and production are mixed together in what has come to be known as the incentive problem: how the cake is divided, i.e., distributive justice, makes a difference for the size of the cake, i.e., efficiency of the production line.

Second, in order for exchange to even be possible, we need to be operating within a system where there exists basic trust and mutual confidence between the various parties to the exchange. In order for the butcher-brewerbaker to go about producing their goods, they must trust that their clients will purchase and pay for goods ordered. To meet orders in a timely fashion, they must rely on suppliers and must trust the delivery people to do their share. Without this form of basic, implicit trust and reliability between the different parties to the exchange, the whole system would collapse. In this respect, the existence of some level of basic trust is an important precondition to cooperation (Donaldson, 2001; Hackley, 2000; Volery, 1998).

Turning from trust to the value of cooperation itself, Rawls provides us with a good starting point from which to assess cooperation, even though he speaks only about, what he calls, "social cooperation”, by which he means cooperation between free and equal citizens in a political society. Rawls understands that the basic question of justice is a question about the fair terms of social cooperation, "I begin with the first fundamental question about political justice in a democratic society, namely what is the most appropriate conception of justice for specifying the fair terms of social cooperation between citizens regarded as free and equal, and as fully cooperating members of society” (Rawls, 1996: p. 3).

His argument can be taken to suggest that there are two fundamental ethical questions that should be asked regarding the value of cooperation. The first question is about the fairness of cooperation: Is cooperation based on fair terms cooperation? The second is a question of rationality: does it make sense? Is it rational for a particular individual to participate in this cooperation? What are "fair terms" of cooperation? Clearly this will depend on the social context, the aims and aspirations of the participants, how they regard themselves and one another as individuals. Nonetheless, according to Rawls, "Fair terms of cooperation articulate an idea of reci- 
procity and mutuality: all who cooperate must benefit, or share in common burdens, in some appropriate fashion" (Rawls, 1996: p. 301).

Finally, the value of cooperation can be evaluated in terms of its outcomes. In the business world, cooperation is a means and not an end. It is not valuable in itself; it is a means that has the potential to bring about very positive ends. However, there are certain intrinsic values that go together with cooperation: values such as working together towards a common goal, the values of communication, respect for others and sharing a goal, that are important side benefits of cooperation.

Is there then a conflict between self-interest and cooperation? At times, when cooperation is based on the first three senses of cooperation discussed above, cooperation is in everyone's self-interest, though sometimes for different reasons. Each party to the cooperative endeavor decides to cooperate in order to promote its own self-interest. The more interesting case is the fourth case, where cooperation is based on the "communitarian notion of teamwork". It is in this case that we see how limited the Smithian notion of self-interest really is. Let's work with an example. Are basketball players who cooperate with a team sacrificing their own self-interests as basketball players? For instance, when they do not receive the ball, and instead serve as a human shield to block a teammate's way of game, are they, as individuals, being used? It seems clearly that the answer is no. Although at a certain level the individual players clearly want to handle the ball and shoot the basket themselves, they have other interests as well. Their interests as ballplayers are much broader. They want their team to win. After all, the success of his team is tantamount to their own success. They want their team to play well, for when the team plays well so do they as individual players. If they were asked to choose between handling the ball themselves, and possibly loosing the game as opposed to cooperating with the team and winning, I believe that any real player would opt for the latter.

As I have tried to show, organizations as well as individuals can work together and collaborate in several different ways. From an ethical point of view, some forms of cooperation can be judged as better, more moral, more enriching, and more fulfilling than other forms of cooperation. Just as individuals can achieve more through cooperation, so can the business community. The analysis of the formal features of the concept of cooperation has showed that cooperation is essentially about working together towards a common goal. The notion of working together does not suppose that both sides to the cooperation are doing the same thing, but it does presuppose that both act within some sense of collaboration or teamwork. The notion of common goal does not rule out the existence of personal interests, but it does require that their personal interests do not clash too strongly, are sufficiently linked with their common goals, and are not overly antagonistic. The articulation of the four schemes of cooperation, which followed this analysis of the formal features of the concept of cooperation, revealed four basic schemes within which organizations can work together towards a common goal.

\section{References}

Anderson, J. C., \& Narus, J. A. (1990). A Model of Distributor Firm and Manufacturer Firm Working Partnerships. Journal of Marketing, 54, 42-58. http://dx.doi.org/10.2307/1252172

Annad, B., \& Khanna, T. (2000). Do Firms Learn to Create Value? The Case of Alliances. Strategic Management Journal, 21, 295-316. http://dx.doi.org/10.1002/(SICI)1097-0266(200003)21:3<295::AID-SMJ91>3.3.CO;2-F

Argandona, A. (1999). Sharing out in Alliances: Trust and Ethics. Journal of Business Ethics, 21, 217-228. http://dx.doi.org/10.1023/A:1006206812389

Arrow, K. J. (1973). Social Responsibility and Economic Efficiency. Public Policy, 21, 303.

Axelrod, R. (1984). The Evolution of Cooperation. New York: Harper Collins Publishers.

Balakrishnan, S., \& Koza, M. P. (1993). Information Asymmetry, Adverse Selection and Joint Ventures. Journal of Economic Behavior and Organization, 20, 99-117. http://dx.doi.org/10.1016/0167-2681(93)90083-2

Beamish, P. W., \& Killing, J. P. (Eds.) (1997). Cooperative Strategies: European Perspectives. San Francisco, CA: The New Lexington Press.

Bleeke, J., \& Ernst, D. (1991). How to Win in Cross boarder Alliances. Harvard Business Review, 69, 127-135.

Brynen, R. (2002). Investment in Peace: The Politics of Cooperation between Israel, Jordan and the Palestinians. Journal of Palestinian Studies, 31, 102-103.

Chan, S., Kensinger, J., Keown, A., \& Martin, J. (1997). Do Strategic Alliances Create Value? Journal of Financial Economics, 46, 199-221. http://dx.doi.org/10.1016/S0304-405X(97)00029-9 
Davidson, D. (2001). Subjective, Intersubjective, Objective: Philosophical Essays Volume 3 (pp. 95-106). Oxford: Clarendon Press. http://dx.doi.org/10.1093/0198237537.003.0007

de Waal, F. (1989). Chimpanzee-Politics: Power and Sex among Apes. Baltimore, MD: John Hopkins University Press.

Donaldson, T. (2001). The Ethical Wealth of Nations. Journal of Business Ethics, 31, 25-36. http://dx.doi.org/10.1023/A:1010776922597

Freeman, R. E. (1984). Strategic Management: A Stakeholder Approach. Boston, MA: Pitman.

Gauthier, D. (1986). Morals by Agreement. Oxford: Clarendon Press.

Gulati, R. (1998). Alliances and Networks. Strategic Management Journal, 19, 293-317. http://dx.doi.org/10.1002/(SICI)1097-0266(199804)19:4<293::AID-SMJ982>3.0.CO;2-M

Hackley, C. E. (2000). Review Article: In Trusts We Trust. Business Ethics: A European Review, 9, 119-121. http://dx.doi.org/10.1111/1467-8608.00181

Harrington, K. R. (1985). Strategies for Joint Ventures, Lexington, MA: Lexington Books.

Held, D. et al. (1999). Global Transformations: Politics, Economics and Culture. Cambridge: Polity Press.

Hobbes, T. (1992). Leviathan (1651). Cambridge: Cambridge University Press. (Tuck, R., Ed.)

Kanter, R. M. (1989). When Giants Learn to Dance. New York: Simon and Schuster.

Kogut, B. (1989). The Stability of Joint Ventures: Reciprocity and Competitive Rivalry. The Journal of Industrial Economics, 38, 183-198. http://dx.doi.org/10.2307/2098529

Maitland, I. (1985). The Limits of Business Self-Regulation. California Management Review, 27, 132-147. http://dx.doi.org/10.2307/41165147

Malcolm, N. (1972). Thoughtless Brutes. Proceedings and Addresses of the American Philosophical Association, 46, 5-20. http://dx.doi.org/10.2307/3129585

Powell, W. M. (1990). Neither Market nor Hierarchy; Network Forms of Organization. In B. M. Staw, \& L. L. Cummings (Eds.), Research in Organizational Behavior (Vol. 12, pp. 295-336). Greenwich, CT: JAI Press.

Rawls, J. (1971). A Theory of Justice. Cambridge, MA: Harvard University Press.

Rawls, J. (1996). Political Liberalism. Cambridge, MA: Harvard University Press.

Reuer, J. J. Maurizio, Z., \& Singh, H. (2001). Post-Formation Dynamics in Strategic Alliances. Strategic Management Journal, 23, 135-151. http://dx.doi.org/10.1002/smj.214

Ring, P. S., \& Van de Ven, A. H. (1994). Developmental Processes of Cooperative Interorganizational Relationships. The Academy of Management Review, 19, 90-118.

Rousseau, J. J. (1967). The Social Contract. Washington, DC: Washington Square Press.

Rousseau, J. J. (1997). The Discourses and other Early Political Writings. Cambridge: Cambridge University Press. (Gourevitch, V., Ed. and Translated)

Sen, A. (1987). On Ethics and Economics. Oxford: Blackwell Publishers.

Sen, A. (1993). Does Business Ethics Make Economic Sense. Business Ethics Quarterly, 3, 45-54. http://dx.doi.org/10.2307/3857381

Skyrms, B. (2001). The Stag Hunt. Proceedings and Addresses of the American Philosophical Association, 75, 31-41. http://dx.doi.org/10.2307/3218711

Smith, A. (1776). An Inquiry into the Nature and Causes of the Wealth of Nations. K. Sutherland (Ed.), Oxford: Oxford University Press. http://dx.doi.org/10.1093/oseo/instance.00043218

Solomon, R. (1994). Above the Bottom Line. San Diego, CA: Harcourt Brace Pub.

Southwick, C. H. (1963). Primate Social Behavior. Princeton, NJ: Van Nostrand Company.

Volery, T., \& Mansik, S. (1998). The Role of Trust in Creating Effective Alliances: A Managerial Perspective. Journal of Business Ethics, 17, 987-994. http://dx.doi.org/10.1023/A:1006054912880

Waddock, S. A. (2002). Leading Corporate Citizens: Vision, Values, Value-Added. Boston, MA: McGraw-Hill.

Watts, D. P. (2002). Reciprocity and Interchange in the Social Relationship of Wild Male Chimpanzees. Behavior, 139, 343370. http://dx.doi.org/10.1163/156853902760102708

Werhane, P. (1991). Adam Smith and His Legacy for Modern Capitalism. Oxford: Oxford University Press. 